\title{
Beobachtungen und Elemente des Cometen I. 1866.
}

Mitgetheilt von Herrn Professor d'Arrest, Director der Sternwarte in Kopenhagen.

Auf der Kopewhagener Sternwarte sind bisher, in kurzen Wolkenlücken, nur nachstehende Beohachtungen des Tempelschen Cometen gelungen:
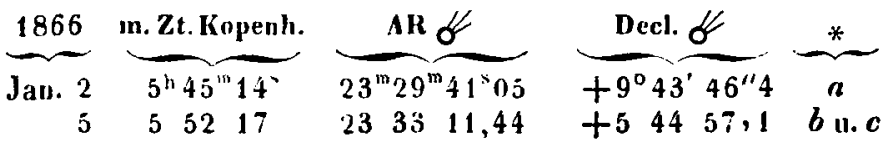

gegrüindet auf diese mittleren Sternörter fïr 1866,0:

$$
\text { a. . . } 23^{\mathrm{h}} 29^{\mathrm{m}} 26^{\mathrm{s}} 01+9^{\circ} 45^{\prime} 51^{\prime \prime} 5 \text { nach Bessel. }
$$

b. . 233142,58 t5 3015,3 nach Lalande,

c... $233220,27+52737,0$ mach L., B. u. Schjel.

Herr Stud. Pechiile hieraelbst, der früher auf dem Institut de prop. fide studirt hat, berechnete die Bahn dieses Cometen bei 12 -tägrigen Intervalle so:

$$
\begin{aligned}
& T=1866 \text { Jan. 9,42997 mittl. Zt. Berl. } \\
& \pi=62^{\circ} 17^{\prime} 6^{\prime \prime} 2 \\
& \Omega=2302958,0\} \\
& i=1786,9 \\
& \log q=9,992078 \text {. } \\
& \text { Retrograd. }
\end{aligned}
$$

Er hat dabei auf die Correctionen Rücksicht genommen: eine noch bessere Anräherung an die wahre Bahn dieses Cometen, die sich erreichen lässt, wird derselbe junge Astronom bald mitheilen.

Nach dem Biela'schen Comete n hahe ich seit August v. J., mit Aufopferung von mehr als 20 Nächten, anhaltend und ernstlich gesucht. Es ist alle Mühe vergeblich gewesen, ohgleich der Comet, den früheren Erfahrungen gemäss, schon seit einiger Zeit gut im Cometensucher sichthar sein müsste. Meine Nachforschungen waren so eingerichtef, dass es kaum denkbar ist, ler Biela'sche Comet passire diesmal seine Sonnennähe innerhalb des Zeitraums \pm 8 Tage von der berechneten Perihelpassage. Auscheinend führen uns verschiedene Thatsachen mehr und mehr zu der Annabme, dass die Cometen vou kurzer Unlanfszeit nicht lange Zeit unserem Systeme angehört hahen, und dass die Materie derselben sich ziemlich hurtig zerstreue.

Kope uhage, 1866 Jan. 7.

d'Arrest.

\section{Entdeckung eines neuen Planeten, nebst einer Beobachtung des Planeten (85),} von Herrn Dr. F. Tietjen.

Als ich am 4. Januar den Planeten 85 aulsuchen wolle, verglich ich einen Stern, der mit den Ephemeridenorte nach Peters Elementen sehr nahe stimmte, mit eincm andern, der sich um $7^{1 /} 50^{\text {n' }}$ nittl. Berl. Zt. etwa $3^{\prime}$ südl. hefand und $5^{5} 9$ voranging. Nach $50^{\prime \prime \prime}$ fand ich zwischen beiden Ohjecten fast gar keine relative Bewegung, wohl aber hatten sie sich heide gegen einen dritten Stern um etwa 2 'bewegt. Da ich diesen aber wur oherflächlich mit den beiden andern verglichen hatte, so vermuthete ich einen Fehler heim Zühlen der Secunden. Ein ferneres Beobachten an diesem Abend gestatteten weder der aufgegangene Mond unch der nit Cirri bedeckte Himnel. An 5. Januar waren die beiden zuerst erwähnten Sterwe von dem Orte, welchen sie am $4^{\text {ton }}$ inne halten, verschwunden, an dem Ephemeridenort tür $\overparen{85}$, stand lagegen wieder ein Stern. Ihn ging $10^{\text {s }} 4$ voran und I' nördlicher ein anderer, den ich sofort lïr einen neuen Planeten bielt, da ich diese Gegend am Abend vorher flüchtig durchmustert hafte. Die nach wenigen Minuten erfolgte Bewegung heider Objecte gegen andere Sterne bestätigte dies, Beobachtungen waren jedoch unmöglich, da der Ilimmel sich plötzlich liedeckte. Erst gestern Abend komnte ich folgende Positionen erlangen:

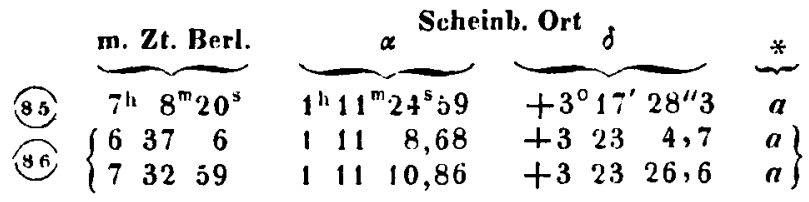

Mittlerer Ort des Vergleichsterns für 1866,0 :

$1^{\mathrm{h}} 11^{\mathrm{m}} 46^{\mathrm{s}} 10+3^{\prime \prime} 24^{\prime} 4^{\prime \prime} 2$ Mer.-Beol. von Romberg.

Die relative Bewegung heider Planeten ist also (86-85:

Jan. $47^{\mathrm{m}} 50^{\mathrm{m}} \mathrm{m}$. Zt. Berl. $\Delta \alpha=-5^{\circ} 9, \Delta \delta=-3^{\prime}$

$\begin{array}{rrrrrr}5 & 6 & 45 & -10,4 & +1 \\ 6 & 7 & 8 & -14.7 & +5,8 .\end{array}$

Die Declinationsschätaungen sind selır roh. - Die tägliche Bewegung des Planeten (86, folgt: $\Delta \alpha=+57^{\prime}, \Delta \delta=$ $+9^{\prime}$ 4. Die Grisse ist 11,9. Wahrscheinlich ist der Planet auch an andern Orten bei Beobachtungen von 8.5 gefunden.
Berlin, 1866 Jan. 7.
F. Tietjen. 